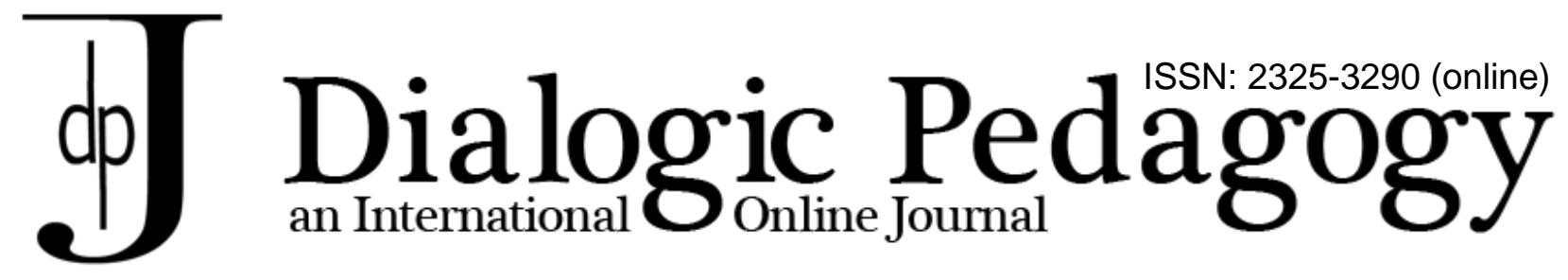

\title{
Bakhtinian pedagogy is needed in our postmodern world
}

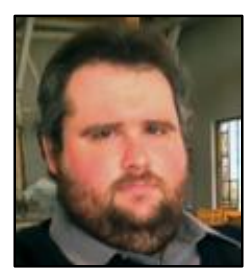

Mikhail Gradovski

University College of Telemark, Norway

\begin{abstract}
Book review: E. Jayne White \& Michael A. Peters (Eds) (2011) Bakhtinian Pedagogy: Opportunities and Challenges for Research, Policy and Practice in Education across the Globe. Peter Lang Publishing.
\end{abstract}

Pascal Bruckner, one of France's leading public intellectuals, writes in his Tyranny of Guilt that the worst that threatens us is indifference: not arousing either enough interest or enough anger in others to justify their malice. For the sphere of education in the western world there exists a danger. This danger is a regime of management, which is based on a present-day positivistic (postpositivistic) idea of a human being. This regime among other things is characterized in some Western countries by an accountability craze, which understands almost any form of relation between a teacher and a learner that leads to learning to be a service. Sometimes this service is even understood as being the same as a very benign and purely instrumental act of selling toothpaste to a customer in a convenience store. In the case of education, we are talking about the service of selling learning as a commodity. The current regime of institutionalized education requires everything about learning to be counted and phenomena that cannot be counted are required to be reported using prearranged forms. The educationalists and teachers' indifference to this regime is this regime's best helping hand. The contributors to this anthology are anything but indifferent to the regime. I see a parallel between the authors of this anthology and Mikhail Bakhtin, who being in opposition to the Soviet indoctrination continued writing his papers understanding that there was small, if any, chance to see them published and read by a wider public in his lifetime. Similarly, the contributors to this book have produced an anthology, which challenges many of the conventional ideas about learning and human being that this regime of educational management is based upon. The contributions in this anthology provide consistent arguments and deeper understanding of the relations between people that result in learning. These arguments and understandings are manifested in the valid pieces of research that show that not everything in the relations that nurtures learning can and should be counted. The authors of the chapters have produced very compulsive and overwhelming evidence on why Bakhtinian pedagogy is needed in our postmodern world. The chapters cover the main themes of Bakhtin's thought that could be related to education as an area of theory and practice: the role of laughter, authorship, dialogue, heteroglossia, chronotope and carnival. The chapters vary in quality and style of writing but their scope and overall quality is convincing enough. For me, this anthology appears to 
be a must read for everyone who wants to get knowledge on the current use of Bakhtin's ideas in the sphere of education. By not being indifferent the contributors have given us, educationalists and teachers, hope and made us thirsty for more.

\section{The Hope}

What makes a good anthology? In my opinion, there should be at least three ingredients: sophisticated research, well founded points of view and sets of argumentation that shed light on a topic in a thought-provoking way providing an opportunity for a dialogue, and content that inspires a reader interested in the topic to desire to get more knowledge. All these ingredients are present in this anthology. The anthology contains introduction, three parts and information about the authors of the chapters. In the introduction the editors give a more or less detailed presentation of the themes touched upon in each part and present a short overview of the main works of inspired by Bakhtin's ideas. This overview is a wellcrafted piece of the historiographical research on Bakhtin. The overview provides information on Bakhtin's theoretical heritage as it has been understood and used in the sphere of education in the Western culture during the last decade. The anthology inspires, provokes and makes one want to get more knowledge and ask questions. Among these the most pronounced is the question of what should be done in practice in order to make Bakhtinian pedagogy to be a part of our everyday educational practice.

\section{The thirst for more}

Among the most inspiring is the chapter "Too Serious: Learning, Schools, and Bakhtin's Carnival" by Timothy J. Lensmire on the use of laughter in educational practice. The author has provided a convincing argument for why the laughter should be a part of pupils' classroom experience. However, the question of how it should be done in practice remains. Another important piece of research in the anthology is a chapter by Jayne E. White "Aesthetics of the Beautiful: Ideologic Tensions in Contemporary Assessment". It is one of the most convincing and beautifully written pieces on the use of assessment and the need of inclusion of the subjective view into the assessment practices in schools and pre-school educational establishments. This chapter contains arguments that empower and inspire, and above all, makes one wanting more. It creates the thirst for more research and knowledge on the subject. Eugene Matusov's chapter "Authorial Teaching and Learning" describes the concept of the authorial learning in a fresh and unconventional yet convincing way. Matusov and White's chapters both inspired me the most and provoked me to ask questions. The very questions and answers to these questions are to be found at the end of this review. Among the chapters that can provoke in a positive way is "The Bakhtin Circle, Philosophy of Language, and Educational Theory" written by Michael Peters. The author has taken upon himself a very uneasy and demanding task of considering the claim whether Bakhtin is the one of (co)-authors behind Voloshinov's texts. I do believe the results of the brilliant analysis Peters has produced. At the same time, the analysis by Peters is not enough. There is a need for an analysis where Bakhtin, Medvedev and Voloshinov's ideas and theories are considered on, at least, three levels: epistemological, ontological and axiological. Only after such analysis is carried out can the claims of Bakhtin's authorship or co-authorship of the texts by Voloshinov and Medvedev be put to rest. I also have problems agreeing with Peters about an existence of the philosophy of education by Voloshinov and, consequently, Bakhtin. Neither Voloshinov nor Bakhtin were interested in creating their own philosoph(y)ies of education. The Bakhtinian philosophy of education does exist. This philosophy is created and developed not by Bakhtin himself, as he wrote only one piece devoted specifically to 
education, but by those who got inspired by Bakhtin's ideas and analysis of human existence, culture and language. This well-crafted anthology, in my opinion, is one of the most important contributions to the body of the Bakhtinian philosophy of education, in particular, and Bakhtinian pedagogy in general.

\section{(cc) EY}

Articles in this journal are licensed under a Creative Commons Attribution 3.0 United States License.

\section{UILIS D-Soulf}

This journal is published by the University Library System, University of Pittsburgh as part of its D-Scribe Digital Publishing Program and is cosponsored by the University of Pittsburgh Press. 